\title{
Editorial
}

\section{0 at 1000: transforming titania take two}

\author{
Christopher F. Blanford ${ }^{1,2, *}$ (ID) \\ ${ }^{1}$ Department of Materials, University of Manchester, Oxford Road, Manchester M13 9PL, UK \\ ${ }^{2}$ Manchester Institute of Biotechnology, University of Manchester, 131 Princess Street, Manchester M1 7DN, UK
}

Published online:

25 June 2020

(C) Springer Science+Business

Media, LLC, part of Springer

Nature 2020

This editorial is part of our series "1000 at 1000," highlighting the Journal of Materials Science's most highly cited publications as part of the journal's celebration of 1000 issues. In this issue: "Review of the anatase to rutile phase transformation" [1] by D.A.H. Hanaor and C.C. Sorrell from the University of New South Wales in Sydney, Australia.

Our editor-in-chief, Barry Carter, sends me almost all the submissions to this journal that feature titanium oxides, so it was no surprise when I was voluntold to write about this review article from 2011, one of our "Sapphire Prize" finalist articles [2, 3].

Hanaor and Sorrell's "Review of the anatase to rutile phase transformation" [1] captured my attention from the first paragraph (emphasis mine): "The likely effects of dopant elements, including those for which experimental data are unavailable, on the phase transformation are deduced." I have handled over 100 submissions of review articles, and this publication has all the hallmarks of a great one: timely, authoritative, comprehensive, critical and predictive. Think to yourself about how many review articles you have read and found useful, that tick all these boxes rather than being simply a summary of publications. And how many have used their literature analysis to make predictions?

At the heart is the most important phase change in titania: above a critical temperature-one that depends on time, atmosphere, dopants and a half-dozen other factors noted by the authors-the relatively open structure of metastable anatase (Fig. 1a) densifies to the thermodynamically stable rutile (Fig. 1b). This transformation changes not only the ceramic's morphology, but also its photocatalytic activity. About 20-30\% of the 100,000 + publications on titania study photocatalysis, so the scientific impact of a clear review was certain to be widespread. "Yet up until the publication of my review paper," Dr. Hanaor wrote to me, "there was no work comprehensively addressing this transformation and the literature relating to this was spread across a broad range of anecdotal observations."

Address correspondence to E-mail: christopher.blanford@manchester.ac.uk 


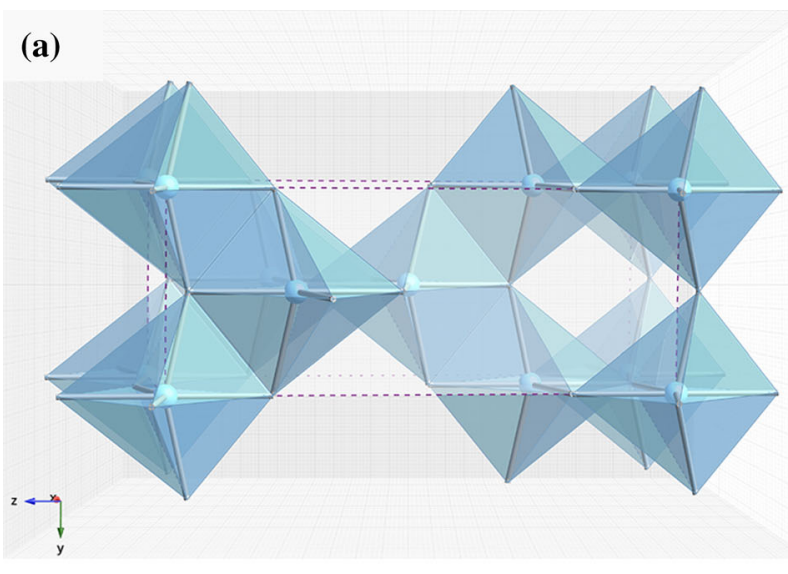

(b)

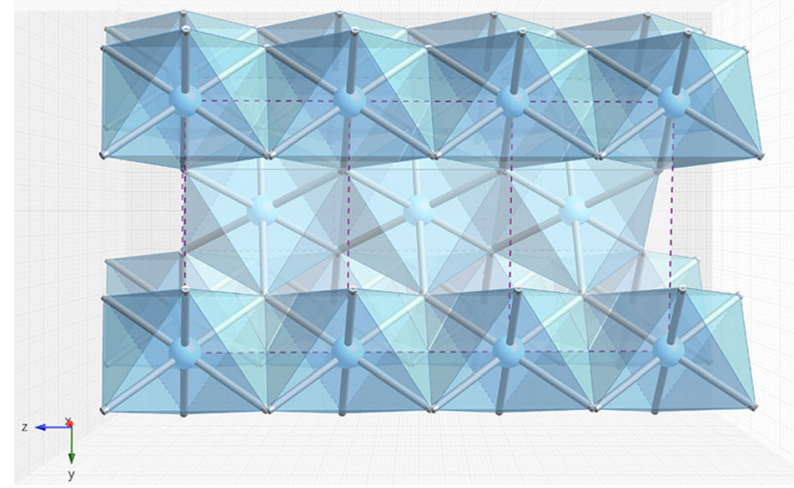

Figure 1 Representations of the structures of the two featured $\mathrm{TiO}_{2}$ polymorphs, $\mathbf{a}$ anatase and $\mathbf{b}$ rutile, represented as octahedra with the titanium ion at the center. The scale is the same for both panels. The octahedra are more densely packed in the rutile structure, consistent with it having a density about $9 \%$ higher than anatase.

During his doctoral research, he saw how additives affected this transition in bulk titania, powders and films. "In seeking answers to the observed phenomena, I found a tremendous amount of literature and observations that were screaming for some sense to made from them. In creating this review, I sought to put as much information as possible into one place, in order to create coherence in the field. The goal was to better understand this transformation and help others understand it better."

What of the predictive element of the work? The authors devised a simple model based on ion valence and its radius and classified published reports of dopants as either promoting the anatase-to-rutile transition or inhibiting it (Fig. 2). I did a cursory search of the literature before contacting the authors. Some predicted promoters, like $\mathrm{Mg}^{2+}$ and $\mathrm{Be}^{2+}$, still haven't been systematically studied. The authors'

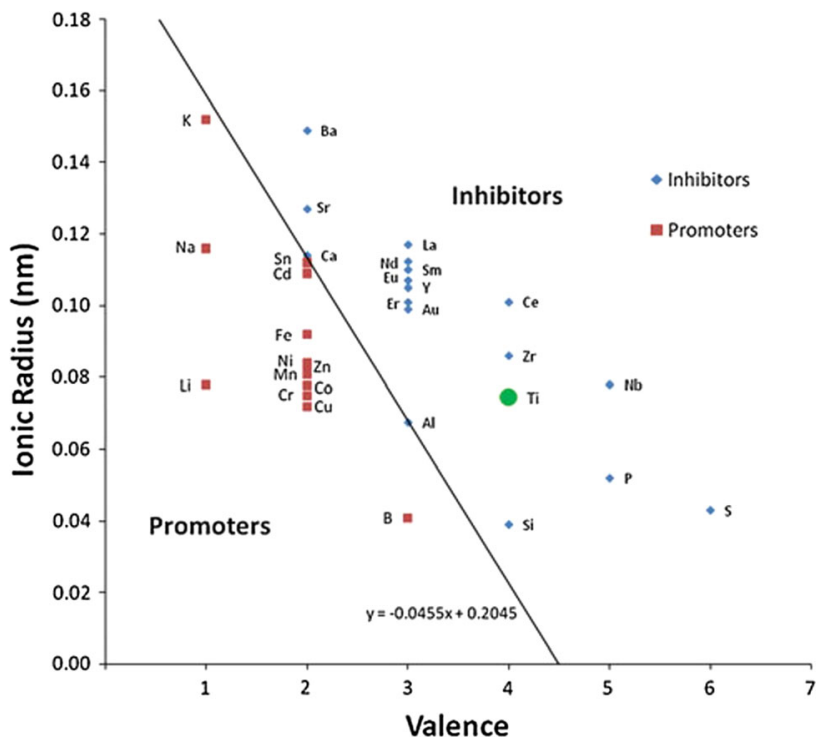

Figure 2 The simple model used by Hanaor and Sorrell to predict which dopants would lower the anatase-to-rutile transition temperature (promoters) and which would raise it (inhibitors). Reproduced from [1].

prediction that $\mathrm{Ag}^{+}$would promote the transition has since been validated $[4,5]$. They predicted that $\mathrm{Pd}$ should be a promoter, but $\mathrm{Pd}^{2+}$ (and higher valences) has been shown to be an inhibitor [6]. However, the data for six-coordinate $\mathrm{Pd}$ ions places the element very close to their transition line [7].

Carbon and nitrogen, used to shift titania's band gap into the visible region, were predicted to be promoters. The authors attached some caveats to their analysis related to carbon's assumed valence state and it acting as a reducing agent as elevated temperature. Contrary to their prediction, a study using multiwalled carbon nanotubes as a carbon source suggested that carbon inhibited the transition [8]. Nitrogen was assumed to substitute on the oxygen lattice, increase the number of oxide vacancies and thus promote the transformation. Experimental reports on the effect of nitrogen on the anatase-to-rutile transition have been mixed: a few have stated it was a promoter [9-11], but the majority classified it as an inhibitor [12-22].

Dr. Hanaor called the linear formula "too simplistic" in his correspondence with me, but he offered that the smaller lower valence cations promote the transformation as a rule of thumb. He pointed to improvements in DFT as a way forward in the study of the transformation [23-31].

What is next for titania? Surprisingly, Dr. Hanaor commented that despite the vast number of publications on the various polymorphs of titania, its only 


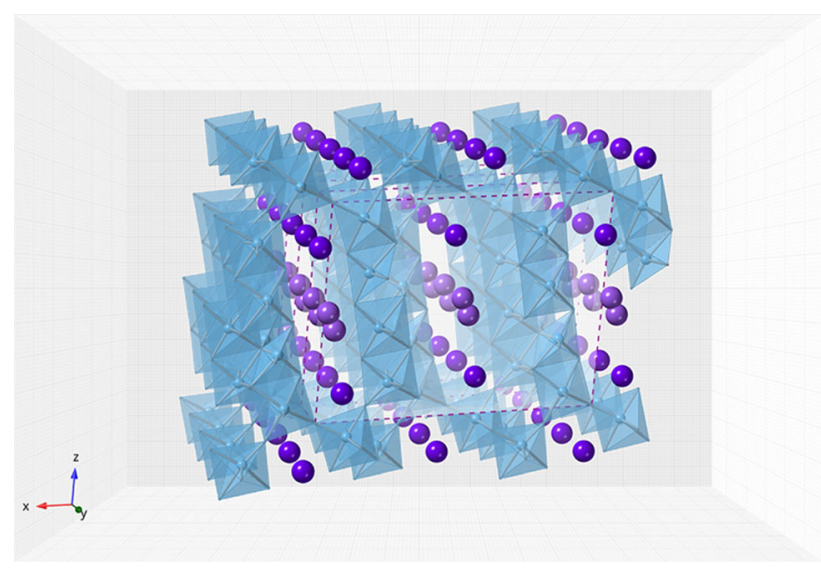

Figure 3 Polyhedral representation of a bronze titania, $\mathrm{K}_{3} \mathrm{Ti}_{8} \mathrm{O}_{17}$, oriented to emphasize the ion channels along the $\mathrm{b}$ axis. The pair of purple $\mathrm{K}^{+}$ions at the center of the channels have $50 \%$ occupancy in the crystal structure [32]. The field of view is three times larger than in Fig. 1.

significant application has been in pigments. He flagged "bronze titania" (Fig. 3) as a material that merits further investigation. Also known as $\mathrm{TiO}_{2}(\mathrm{~B})$, this material contains $\mathrm{Ti}(\mathrm{III}), \mathrm{Ti}(\mathrm{IV})$ and additional small cations to balance the charge [32, 33], and it has been considered as a high-rate ionic conductor for lithium-ion batteries [34, 35].

Dr. Hanaor is currently teaching courses on ceramics, energy materials and nanomaterials at TU Berlin. "I believe that creating valuable insights requires looking at a topic from multiple perspectives," he wrote. "I like to think that I inspire my students to look at problems from multiple angles and apply diverse tools to bring about progress in various fields. Personally, the work on this paper led me to appreciate the value in creating insights from literature sources."

The ca. 50,000 downloads of Hanaor and Sorrell's work from the Springer website is testament to the value of a well-crafted review article.

\section{References}

[1] Hanaor DAH, Sorrell CC (2011) Review of the anatase to rutile phase transformation. J Mater Sci 46(4):855-874. h ttps://doi.org/10.1007/s10853-010-5113-0

[2] The Sapphire Prize: Celebrating the best research published in the journal's Sapphire Anniversary Year (2010) https:// www.springer.com/cda/content/document/cda_downloaddoc
ument/JMSC+Sapphire+Prize+Flyer+Full.pdf?SGWID=0 -0-45-1018737-p35692639. Accessed 06 May 2020

[3] Sapphire Prize Finalists (2011) https://www.springer.com/ma terials?SGWID=0-10041-12-797604-0. Accessed 06 May 2020

[4] Golim OP, Desiati RD, Muslimin AN, Sugiarti E (2019) Morphological evolution of sol-gel synthesized $\mathrm{Ag}-\mathrm{TiO}_{2}$ nanocomposite. J Phys Conf Ser 1191:012049. https://doi. org/10.1088/1742-6596/1191/1/012049

[5] Wu M-C, Lin T-H, Hsu K-H, Hsu J-F (2019) Photo-induced disinfection property and photocatalytic activity based on the synergistic catalytic technique of $\mathrm{Ag}$ doped $\mathrm{TiO}_{2}$ nanofibers. Appl Surf Sci 484:326-334. https://doi.org/10.1016/j.apsusc. 2019.04.028

[6] Zuo Z, Huang W, Han P, Li Z (2009) Theoretical and experimental investigation of the influence of $\mathrm{Co}$ and $\mathrm{Pd}$ on the titanium dioxide phase transition by different calcined temperature. J Mol Struct 936(1):118-124. https://doi.org/ 10.1016/j.molstruc.2009.07.025

[7] Winter M (2020) Web elements_-palladium: radii of atoms and ions. https://www.webelements.com/palladium/atom_si zes.html. Accessed 06 Aug 2020

[8] Xie C, Yang S, Li B, Wang H, Shi J-W, Li G, Niu C (2016) C-doped mesoporous anatase $\mathrm{TiO}_{2}$ comprising $10 \mathrm{~nm}$ crystallites. J Colloid Interface Sci 476:1-8. https://doi.org/10. 1016/j.jcis.2016.01.080

[9] Dong L, Ma Y, Wang Y, Tian Y, Ye G, Jia X, Cao G (2009) Preparation and characterization of nitrogen-doped titania nanotubes. Mater Lett 63(18):1598-1600. https://doi.org/10. 1016/j.matlet.2009.04.022

[10] Nolan NT, Synnott DW, Seery MK, Hinder SJ, Van Wassenhoven A, Pillai SC (2012) Effect of N-doping on the photocatalytic activity of sol-gel $\mathrm{TiO}_{2}$. J Hazard Mater 211-212:88-94. h ttps://doi.org/10.1016/j.jhazmat.2011.08.074

[11] Wu H, Yang D, Zhu X, Gu P, Sun H, Wangyang P, Li J, He $X$, Fan L (2018) Effect of the nitrogen-oxygen ratio on the position of $\mathrm{N}$ atoms in the $\mathrm{TiO}_{2}$ lattice of $\mathrm{N}$-doped $\mathrm{TiO}_{2}$ thin films prepared by DC magnetron sputtering. CrystEngComm 20(29):4133-4140. https://doi.org/10.1039/C8CE00773J

[12] Xue Q, Guan Y, Wang Z, Bai S (2010) Preparation of nitrogen doped $\mathrm{TiO}_{2}$ nanotube arrays and their visible light responsive photocatalytic properties. Acta Chim Sin 68(16):1603-1608

[13] Cheng H-E, Chen Y-R, Wu W-T, Hsu C-M (2011) Effect of nitrogen doping concentration on the properties of $\mathrm{TiO}_{2}$ films grown by atomic layer deposition. Mater Sci Eng B 176(7):596-599. https://doi.org/10.1016/j.mseb.2011.02.001

[14] Chekini M, Mohammadizadeh MR, Vaez Allaei SM (2011) Photocatalytic and superhydrophilicity properties of N-doped $\mathrm{TiO}_{2}$ nanothin films. Appl Surf Sci 257(16):7179-7183. https://d oi.org/10.1016/j.apsusc.2011.03.084 
[15] Ma P, Yan G, Qian J, Zhang M, Yang J (2011) Preparation of novel $\mathrm{N}-\mathrm{TiO}_{2}$ by a solid-state method and its photocatalytic activity. Chin J Catal 32(8):1430-1435. https://doi.org/10. 3724/SP.J.1088.2011.10431

[16] Cheng X, Yu X, Xing Z (2012) Characterization and mechanism analysis of $\mathrm{N}$ doped $\mathrm{TiO}_{2}$ with visible light response and its enhanced visible activity. Appl Surf Sci 258(7):3244-3248. https://doi.org/10.1016/j.apsusc.2011.11. 072

[17] Iwase M, Yamada K, Kurisaki T, Wakita H (2013) Characterization and photocatalytic activity of nitrogen-doped titanium(IV) oxide prepared by doping titania with TiN powder. Appl Catal A 455:86-91. https://doi.org/10.1016/j.apcata.2 013.01 .016

[18] Lin Y-T, Weng C-H, Hsu H-J, Lin Y-H, Shiesh C-C (2013) The synergistic effect of nitrogen dopant and calcination temperature on the visible-Light-induced photoactivity of N-doped $\mathrm{TiO}_{2}$. Int J Photoenergy 2013:268723. https://doi. org/10.1155/2013/268723

[19] Lin S, Zhou T, Lu J, Sun Q (2016) Fabrication of nitrogenmodified $\mathrm{TiO}_{2}$ immobilized on glass-fiber and its photocatalytic activity under simulated solar irradiation. Fresenius Environ Bull 25(11):4837-4847

[20] Li Z, Ren Z, Qu Y, Du S, Wu J, Kong L, Tian G, Zhou W, Fu $\mathrm{H}$ (2014) Hierarchical $\mathrm{N}$-doped $\mathrm{TiO}_{2}$ microspheres with exposed (001) facets for enhanced visible light catalysis. Eur J Inorg Chem 12:2146-2152. https://doi.org/10.1002/ejic. 201301561

[21] Lin Y-H, Weng C-H, Srivastav AL, Lin Y-T, Tzeng J-H (2015) Facile synthesis and characterization of N-doped $\mathrm{TiO}_{2}$ photocatalyst and its visible-light activity for photooxidation of ethylene. J Nanomater 2015:807394. https://doi. org/10.1155/2015/807394

[22] Suwannaruang T, Kidkhunthod P, Chanlek N, Soontaranon S, Wantala K (2019) High anatase purity of nitrogen-doped $\mathrm{TiO}_{2}$ nanorice particles for the photocatalytic treatment activity of pharmaceutical wastewater. Appl Surf Sci 478:1-14. https://doi.org/10.1016/j.apsusc.2019.01.158

[23] Yu DX, Fu M, Ji GF, Chen XR (2009) Phase transition and thermodynamic properties of $\mathrm{TiO}_{2}$ from first-principles calculations. Chin Phys B 18(1):269-274

[24] Zhang SF, Li J, Zeng FG (2015) Influence of V-doped anatase on rutile phase transition by theoretical methods. J Comput Theor Nanosci 12(8):1919-1923. https://doi.org/ 10.1166/jetn.2015.3977

[25] Zhang YF, Shen HY, Liu YH (2016) Cooperation among N, $\mathrm{F}$ and $\mathrm{Fe}$ in tri-doped $\mathrm{TiO}_{2}$ photocatalyst. Res Chem Intermed 42(7):6265-6287. https://doi.org/10.1007/s11164-016$2460-8$
[26] Zhang YF, Shen HY, Liu YH (2016) Synergistic effects of F and $\mathrm{Fe}$ in co-doped $\mathrm{TiO}_{2}$ nanoparticles. J Nanopart Res 18:60. https://doi.org/10.1007/s11051-015-3258-0

[27] Esfandfard SM, Elahifard MR, Behjatmanesh-Ardakanii R, Kargar H (2018) DFT study on oxygen-vacancy stability in rutile/anatase $\mathrm{TiO}_{2}$ : effect of cationic substitutions. Phys Chem Res 6(3):547-563. https://doi.org/10.22036/pcr.2018. 128713.1481

[28] Ho DQ, Kim S (2018) Role of aluminum doping in anataseto-rutile transformation from thermodynamic view point. Phys Status Solidi Rapid Res Lett 12:1800234. https://doi. org/10.1002/pssr.201800234

[29] Morgade CIN, Castellani NJ, Cabeza GF (2018) Theoretical analysis of band alignment and charge carriers migration in mixed-phase $\mathrm{TiO}_{2}$ systems. J Comput Electron 17(4):1505-1514. https://doi.org/10.1007/s10825-018-12327

[30] Byrne C, Moran L, Hermosilla D, Merayo N, Blanco A, Rhatigan S, Hinder S, Ganguly P, Nolan M, Pillai SC (2019) Effect of $\mathrm{Cu}$ doping on the anatase-to-rutile phase transition in $\mathrm{TiO}_{2}$ photocatalysts: theory and experiments. Appl Catal B Environ 246:266-276. https://doi.org/10.1016/j.apcatb.20 19.01 .058

[31] Kumaravel V, Rhatigan S, Mathew S, Bartlett J, Nolan M, Hinder SJ, Sharma PK, Singh A, Byrne JA, Harrison J, Pillai SC (2019) Indium-doped $\mathrm{TiO}_{2}$ photocatalysts with hightemperature anatase stability. J Phys Chem C 123(34):21083-21096. https://doi.org/10.1021/acs.jpcc.9b 06811

[32] Watts JA (1970) $\mathrm{K}_{3} \mathrm{Ti}_{8} \mathrm{O}_{17}$, a new alkali titanate bronze. J Solid State Chem 1(3):319-325. https://doi.org/10.1016/ 0022-4596(70)90111-8

[33] Marchand R, Brohan L, Tournoux M (1980) $\mathrm{TiO}_{2}(\mathrm{~B})$ a new form of titanium dioxide and the potassium octatitanate $\mathrm{K}_{2} \mathrm{Ti}_{8} \mathrm{O}_{17}$. Mater Res Bull 15(8):1129-1133. https://doi.org/ 10.1016/0025-5408(80)90076-8

[34] Dylla AG, Henkelman G, Stevenson KJ (2013) Lithium insertion in nanostructured $\mathrm{TiO}_{2}(\mathrm{~B})$ architectures. Acc Chem Res 46(5):1104-1112. https://doi.org/10.1021/ar300176y

[35] Opra DP, Gnedenkov SV, Sinebryukhov SL (2019) Recent efforts in design of $\mathrm{TiO}_{2}(\mathrm{~B})$ anodes for high-rate lithium-ion batteries: A review. J Power Sources 442:227225. https://doi. org/10.1016/j.jpowsour.2019.227225

Publisher's Note Springer Nature remains neutral with regard to jurisdictional claims in published maps and institutional affiliations. 